\title{
Innovative technique for rapid in vitro multiplication of rootless shoots in Andrographis paniculata (Burm. f) Nees: A plant with immense pharmaceutical value
}

\author{
Aayeti Shailaja, Mote Srinath, Byreddi Bhavani Venkata Bindu and Charu Chandra Giri* \\ Centre for Plant Molecular Biology (CPMB), Osmania University, Hyderabad-500007, Telangana State, India
}

\section{Article Info}

Article history

Received 11 March 2020

Revised 1 May 2020

Accepted 5 May 2020

Published online 30 June 2020

Keywords

Andrographis paniculata (Burm. f)

Andrographolide

Culture technique

HPLC

\begin{abstract}
Andrographis paniculata (Burm. f) Nees is a treasured medicinal plant having higher amounts of its principal bioactive compound andrographolide in leaves. In the present study, a novel and rapid in vitro propagation technique has been developed for rootless shoot cultures in A. paniculata by evaluating different culture techniques. Rootless shoot cultures were optimally cultivated on Murashige and Skoog (MS) liquid/solid medium, supplemented with $2 \mathrm{mg} \mathrm{l}^{-1}$ benzylaminopurine. Various techniques such as only liquid media, liquid media over blotting paper, liquid media on cotton block, and solid media were evaluated for fast multiplication of $A$. paniculata rootless shoots. Amongst the culture techniques evaluated, a maximum of $131.66 \pm 11.98$ shoots were obtained in liquid medium over blotting paper method after 21 days of culture. The liquid culture technique facilitated shoot multiplication frequency up to $71.66 \pm 8.1$. The liquid medium over blotting paper technique for multiplication of shoots was found the best as compared to other methods evaluated. HPLC analysis in these four techniques revealed that, the shoots grown in liquid media promoted highest andrographolide accumulation of $(4.0 \% \mathrm{DW})$ compared to culture of shoots in solid media normally practiced. The evaluation of different culture techniques revealed the efficacy of culture methods for rapid propagation of $A$. paniculata as a constant source of this elite plant material.
\end{abstract}

\section{Introduction}

Andrographis paniculata (Burm. f) Nees commonly known as "Kalmegh", belongs to family Acanthaceae, is an important medicinal plant and used in traditional medicine in China, South Asian countries. This is also called as "King of bitters" due to the presence of andrographolide (Sajeeb et al., 2015). It has various pharmacological applications (Dai et al., 2019) like, antimicrobial (Xu et al., 2016), antihyper glycemic, anti-inflammatory (Gan et al., 2019), anti-cancerous (Sarkar et al., 2019) and immunestimulatory effects (Subramanian et al., 2012; Kumar et al., 2014) anti HIV properties (Yang et al., 2010). It also showed antimalarial (Widyawaruyanti et al., 2014) hepato protective (Negi et al., 2008) properties. It is used to treat upper respiratory tract infection (Poolsup et al., 2004). The analogues of andrographolide have been reported to possess immune-modulator and antiatherosclerotic effects (Chao et al., 2010). In addition to this, A. paniculata has been generally used for common cold and flu as a conventional medication. It was mentioned in the past that this plant also used as an wonder drug during 1919 Spanish flu pandemic alike current COVID-19 crisis worldwide (Hancke et al., 1995). In a recent report, andrographolide nanocrystals have demonstrated hepatoprotective activity to drug induced liver injury (Basu et al., 2020) and antivenom (Ghosh et al., 2020). Andrographolide extracted from various parts

Corresponding author: Dr. Charu Chandra Giri

Professor and Director, Centre for Plant Molecular Biology (CPMB), Osmania University, Hyderabad-500007, Telangana State, India E-mail: giriccin@yahoo.co.in

Tel.: +99-9949493532 of the plant such as leaves, stems, roots of this plant, the highest content was found in leaves (Sharma et al., 2013). Keeping in view the importance of diterpene lactone andrographolide, the conventional methods for andrographolide production were not sufficient (Padmanabhan et al., 2017). Thus, to overcome the limitations in the continuous supply of andrographolide and related compounds, biotechnological intervention by in vitro propagation (micropropagation) of these plants can be an alternative (Avila, Treviño et al., 2017).

Andrographolide is produced in two important pathways, i.e., Methyl erythritol phosphate (MEP) pathway (plastidal) and Mevlonate (MVA) pathway (cytosolic), with simultaneous contribution of both the pathways (Srivastava and Akhila 2010). However, the andrographolide production may be influenced by different climatic and other conditions (Pandey et al., 2019). Our laboratory is engaged in research initiatives on distribution of $A$. paniculata and related species, pharmacological study and yield enhancement of bioactive compounds, using biotechnological, genomic, proteomic and bioinformatics approaches (Neeraja et al., 2015; Zaheer and Giri, 2015; Parlapally et al., 2016; Giri and Zaheer, 2016; Zaheer and Giri, 2017 (a,b); Bindu et al., 2017; Srinath et al., 2017; Shailaja et al., 2018). Besides the enhanced production of secondary metabolites with particular reference to andrographolide, the elicitation of plant cell, tissue and organ cultures, understanding of molecular basis of elicitation process and secondary metabolism in general at functional level is our envisaged ongoing research goal (Srinath et al., 2020; Bindu et al., 2020). There is a continuous need of in vitro grown plants/plantlets for their exploitation in answering questions on secondary metabolism manipulation, regulation in general and with

Copyright (C) 2020 Ukaaz Publications. All rights reserved.

Email: ukaaz@yahoo.com; Website: www.ukaazpublications.com 
particular reference to A. paniculata. The methods for shoot proliferation in vitro have been used for rapid propagation of plants. In the past, attempts have been made for biomass magnification through multiple shoot cultures using different culture techniques such as solid, liquid and temporary immersion in liquid (Pérez-Alonso et al., 2012; Zuma et al., 2017; Aziz et al., 2018; Arano-Avalos et al., 2019). To substantiate this objective in the present communication, rapid multiplication of shoots for enhanced biomass production in $A$. paniculata is of utmost importance and significance. On this above background, evaluation of different culture techniques was undertaken for the rapid multiplication of shoots in A. paniculata.

\section{Materials and Methods}

2.1 Establishment of $A$. paniculata plants in net house conditions

The dried seeds of $A$. paniculata were procured from Regional Centre of CSIR-Central Institute of Medicinal and Aromatic Plants (CIMAP), Hyderabad, India. Seeds were sown in net house plot (cement structure filled with soil) at Centre for Plant Molecular Biology (CPMB), Hyderabad. The plants were established by regular supplement of Hoagland solution twice daily (Hoagland et al., 1938).

\subsection{Germination of seeds from pods of $A$. paniculata}

The immature green and matured brown pods from 5 months old A. paniculata plants, were collected and washed with Teepol for $10 \mathrm{~min}$ and then surface sterilized with $0.1 \%(\mathrm{w} / \mathrm{v}) \mathrm{HgCl}_{2}$ for $5 \mathrm{~min}$ followed by 5 times washing with sterile distilled water, $5 \mathrm{~min}$ each. The pods were dissected and seeds were inoculated into MS (Murashige and Skoog 1962) medium and incubated at $25 \pm 2{ }^{\circ} \mathrm{C}$ temperature for germination in dark.

2.3 Multiple shoot induction from seedlings of $A$. paniculata in vitro

$\mathrm{MS}+\mathrm{BAP}\left(2 \mathrm{mg} \mathrm{l}^{-1}\right)$ medium was prepared and $\mathrm{pH}$ was adjusted to $5.8 \pm 2$ before adding $0.9 \%(\mathrm{w} / \mathrm{v})$ agar and was autoclaved at $121^{\circ} \mathrm{C}$, $15 \mathrm{lb}$ pressure for $15 \mathrm{~min}$. The cotyledonary nodes from seedlings of A. paniculata were transferred aseptically onto MS nutrient medium for initiation of multiple shoots. The cultures were incubated under cool white fluorescent tube lights at $25 \pm 2{ }^{\circ} \mathrm{C}$ temperature. The sub-culturing of shoots was done once at four week of regular intervals. The shoots were maintained in same solid medium up to two sub culture passages.

2.4 Technique for rapid propagation of $A$. paniculata multiple rootless shoot cultures

Different techniques carried out for multiplication of rootless shoot cultures and are as follows:

a. Semi solid media

b. Liquid media

c. Liquid media over blotting paper

d. Liquid media over cotton block

Semi solid medium: MS + BAP $\left(2 \mathrm{mg} \mathrm{l}^{-1}\right)$ medium was prepared with $9 \%(\mathrm{w} / \mathrm{v})$ agar and the $\mathrm{pH}$ was set to $5.8 \pm 0.2$. About $25 \mathrm{ml}$ melted agar medium was added to each $150 \mathrm{ml}$ flask and closed with cotton plugs.

Liuid medium: Liquid medium with $\mathrm{MS}+\mathrm{BAP}\left(2 \mathrm{mg} \mathrm{l}^{-1}\right)$ was prepared without agar and $25 \mathrm{ml}$ medium was added to each flask.
Liquid media over blotting paper: Blotting paper sheets were cut into small (i.e., one and half inch length and breadth), four slices of paper were taken and placed at the bottom of each flask. Twenty five $\mathrm{ml}$ of same liquid medium MS $+\operatorname{BAP}\left(2 \mathrm{mg} \mathrm{l}^{-1}\right)$ was added to the flasks.

Liquid media over cotton block: The cotton was cut into blocks of one and half inch length and breadth and single cotton block was placed at the bottom of the flask containing $25 \mathrm{ml} \mathrm{MS}+$ BAP medium.

2.5 Inoculation of multiple shoots onto medium using different culture techniques

Single shoot bunch consisting of a minimum of 15 shoots weighing $1.5 \mathrm{gm}$ were taken as explants, inoculated aseptically onto $150 \mathrm{ml}$ Erlenmeyer flasks from 8 -week old cultures initiated and established on both semi solid and liquid MS + BAP $\left(2 \mathrm{mg} \mathrm{l}^{-1}\right)$ medium. The cultures were incubated under 3000 lux light intensity provided by cool white fluorescent tube lights at $25 \pm 2{ }^{\circ} \mathrm{C}$ temperature. Observation was taken after three weeks to evaluate the efficacy of different culture techniques.

2.6 Study of different culture techniques for biomass, andrographolide production in multiple shoot cultures of A. paniculata and quantitative analysis of andrographolide

Three weeks old multiple shoots were taken out from medium and soaked using tissue paper to remove surface moisture and the FW of the shoots were taken. Shoots were further dried in oven dryer for 1 week at $68^{\circ} \mathrm{C}$. Dry weight of shoots was taken, powdered and stored in vials. The samples in methanol were sonicated for half an hour and the resultant extract was filtered using Whatman filter paper No. 41. Further, the final filtration was done by passing extract through $0.45 \mu \mathrm{M}$ membrane (Millex HV, Millipore, Ireland), $500 \mu \mathrm{l}$ of filtrate was taken and transferred to HPLC vials. The different plant samples and shoots established in different techniques were air dried and finely powdered. The fine powder of plant sample $(50 \mathrm{mg}$ ) was placed in a vial containing $5 \mathrm{ml}$ of HPLC (high performance liquid chromatography) grade methanol and incubated for $24 \mathrm{~h}$ at room temperature. The vials were subjected to ultrasonication for $30 \mathrm{~min}$ in ultrasonic cleaning bath. The resultant extract was filtered using Whatman filter paper No. 41. Further, the final filtration was done by passing extract through $0.45 \mu \mathrm{m}$ membrane filter (Millex HV, Millipore, Ireland). About $500 \mu \mathrm{l}$ of filtrate solution was taken and transferred into HPLC vials.

\subsection{HPLC protocol}

The samples were analyzed for andrographolide content using HPLC (Waters, USA). The column employed was Spherisorb C 18 column $(250 \times 4.6 \mathrm{~mm}, 5 \mu \mathrm{M})$. Compounds separation was carried out by isocratic elution with HPLC-grade methanol as mobile phase at $1 \mathrm{ml} \mathrm{min}^{-1}$. Flow rate of the injected sample volume was $0.02 \mathrm{ml}$. The column was maintained at $25^{\circ} \mathrm{C}$ and elution was monitored at $230 \mathrm{~nm}$. The software used was Empower pro and detector was photodiode array detector (PDA) with a retention time of $2.6 \pm 0.3$ min. Authentic standard andrographolide of $98 \%$ purity procured from Sigma Aldrich, USA was used for analysis. Andrographolide content was expressed as \% dry weight (DW) of control and elicited multiple shoot culture samples. 


\subsection{Statistical analysis}

The experiments on in vitro multiplication of shoots were performed three times with a minimum of 9 replicates each. Each replicate is having 15 shoots as a bunch. Latin square experimental design was followed for the experiments and subsequent statistical analysis. The mean value in tables shows the average response of 9 replicates. Analysis such as, Mean, SE, two-way ANOVA, one-way ANOVA and multiple comparisons was done using Matlab Version 5.3, and SPSS version 10.0 Math Works Inc. (USA) statistical packages.

\section{Results}

3.1 Germination of seedlings and multiple shoot induction on solid medium

The immature pod seeds were germinated with a frequency of $73.3 \pm 10.32 \%$ in MSO medium with an average of $7 \pm 2$ days to germination (Figure 1).

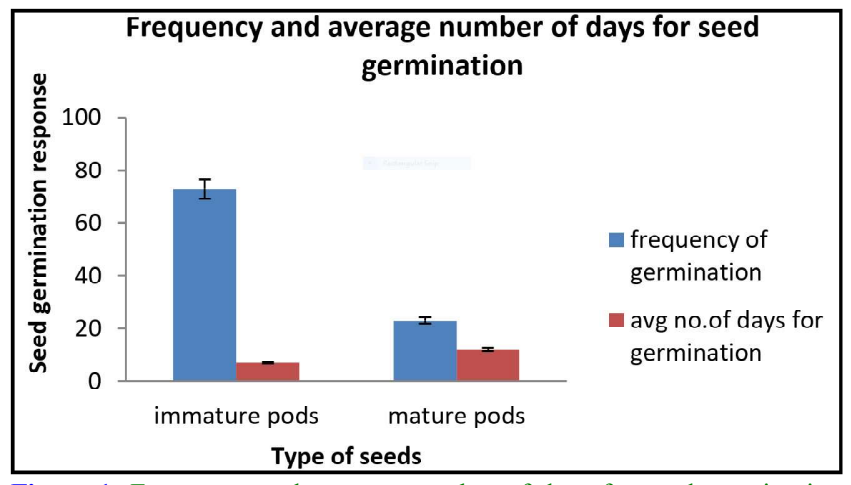

Figure 1: Frequency and average number of days for seed germination from immature and mature pods of $A$. paniculata.

Whereas, the mature pod seeds germinated with a frequency of $23.3 \pm 5.16 \%$ with an average of $12 \pm 3$ days for obtaining germination (Figure 2a). Each seedling gave an average of $3.16 \pm 0.40$ shoots on $2.0 \mathrm{mg} \mathrm{l}^{-1} \mathrm{BAP}$ supplemented medium after 4 weeks of culture. Further, sub-culturing of multiple shoots for duration of 8 weeks on same $2.0 \mathrm{mg} \mathrm{l}^{-1} \mathrm{BAP}$ supplemented medium generated $15.5 \pm 0.42$ shoots (Figures $2 b, 2 c$ ).

\subsection{Influence of different techniques on multiplication of $A$. paniculata rootless shoots}

Growth of shoots using various techniques gave variable response on multiple shoot induction. When the initial inoculums with a small number of shoots (i.e., less than ten shoots) was inoculated into liquid medium, any further shoots were not obtained from these inoculated shoots. But, when a minimum of 15 shoots bunch was inoculated, the growth of shoots was found better.

The shoot number was increased to $61.44 \pm 8.32$ in only liquid, $109.88 \pm 11.3$ in liquid media over blotting paper, $34.55 \pm 3.79$ in liquid media over cotton, $32.22 \pm 3.41$ in solid media after 14 days of culture (Tables 1, 2, 3; Figure 2 and 4). Further, observations revealed $71.66 \pm 8.1,131.66 \pm 11.9,39 \pm 2.5$ and $36.88 \pm 4.1$ shoots in sole liquid, liquid media over blotting paper, liquid media over cotton block and solid media, respectively; after 21 days. The highest number of multiple shoots, i.e., $131.66 \pm 11.98$ was seen in liquid media over blotting paper compared to all other techniques (Tables 3, 4, 5; Figure 3 and 4). Thus a mass scale multiplication of shoots was achieved in liquid media compared to blotting paper.

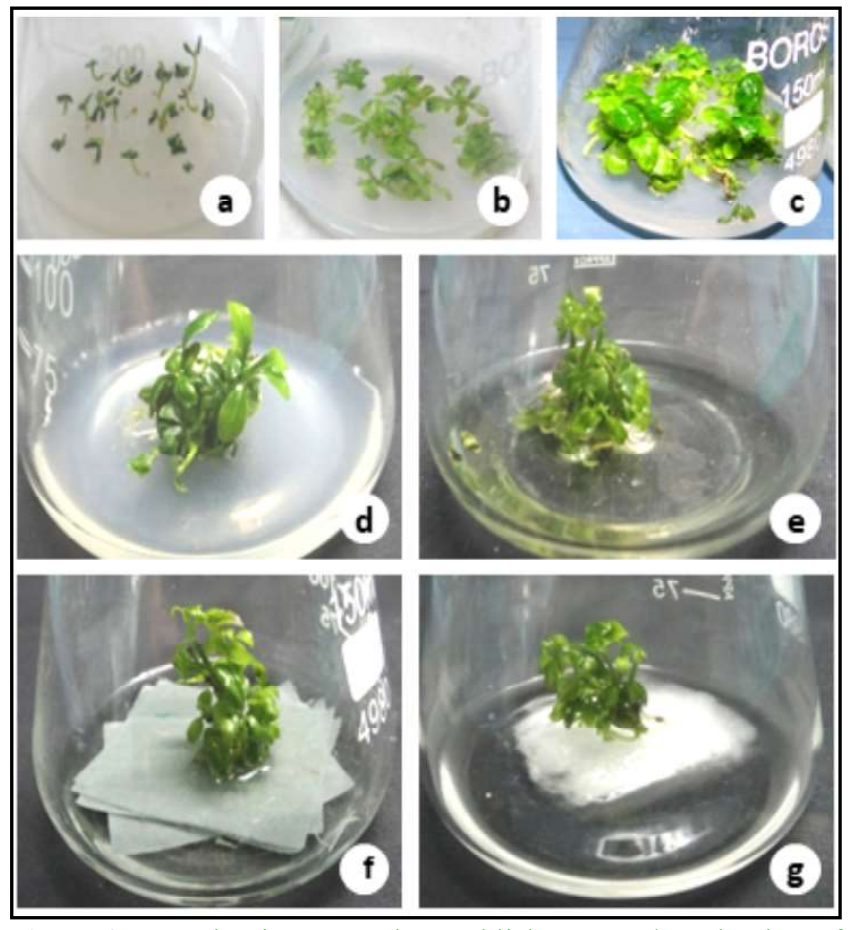

Figure 2: Germination, growth, establishment and evaluation of different culture techniques using multiple shoot cultures of $A$. paniculata. (a) Germinating seedlings from immature pods in MSO medium. (b) Elongation and growth of seedlings (c) Further growth and establishment of multiple shoot cultures. $1^{\text {st }}$ day of multiple shoot inoculation in MS + BAP $\left(2 \mathrm{mg} \mathrm{l}^{-1}\right)(\mathrm{d})$ Semi solid medium (e) Liquid media (f) Liquid media over blotting paper (g) Liquid media over cotton.
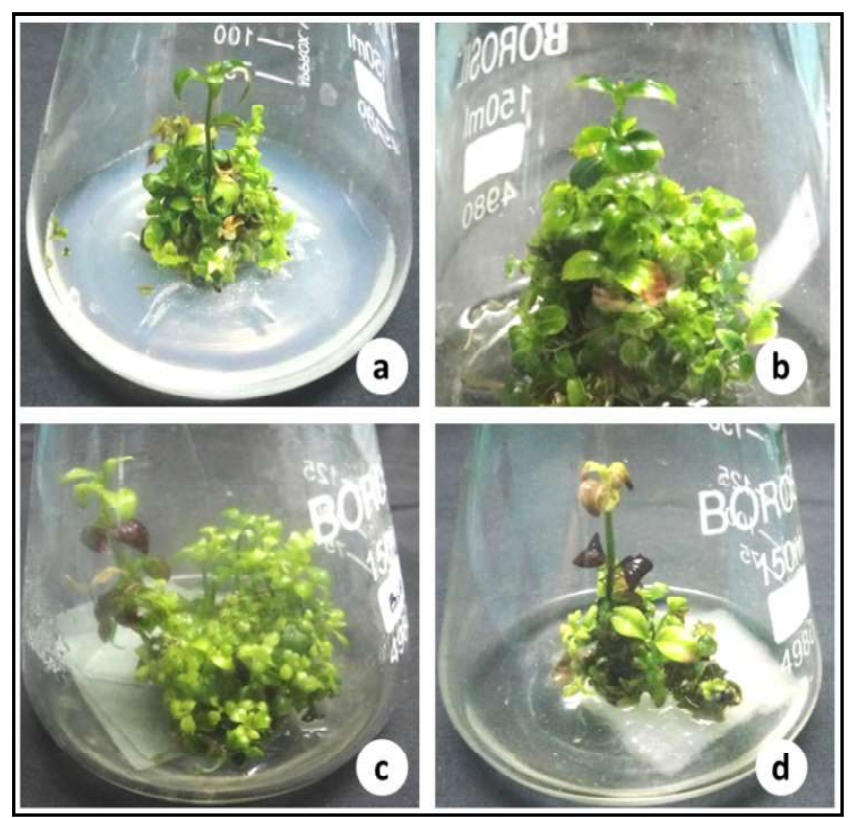

Figure 3: Evaluation of different culture techniques using multiple shoot cultures of $A$. paniculata. 21 days of multiple shoot inoculation in MS + BAP $\left(2 \mathrm{mg} \mathrm{l}^{-1}\right)$ (a) Semi solid medium (b) Liquid media (c) Liquid media over blotting paper (d) Liquid media over cotton. 


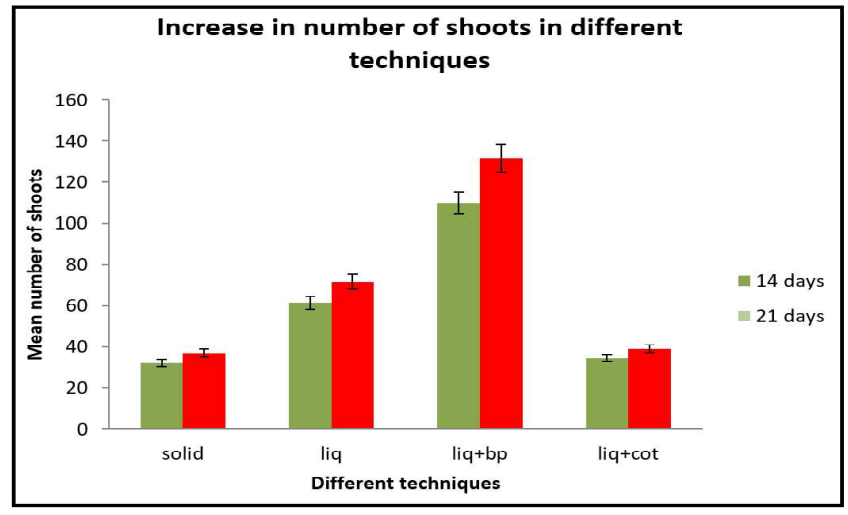

Figure 4: Frequency of multiple shoot induction using different culture techniques in $A$. paniculata. liq: liquid medium; liq+bp: liquid medium over blotting paper; liq+cot: liquid medium over cotton.

Table 1: One-way analysis of multiple shoots growth using different techniques in A.paniculata after 14 days

\begin{tabular}{|l|r|r|}
\hline Culture techniques & \multicolumn{1}{|c|}{ Mean } & Std. error \\
\hline Semi solid & 32.2222 & 3.41475 \\
Liquid & 61.4444 & 8.32184 \\
Liquid media over blotting paper & 109.8889 & 11.35347 \\
Liquid media over cotton & 34.5556 & 3.79368 \\
\hline
\end{tabular}

Observations were recorded after 14 days of inoculation. The experiment was repeated thrice by maintaining minimum of 9 replicates each time. Each replicate consists of $15 \pm 3$ healthy shoots. Mean is the average response of 9 replicates and the mean \% value in the table shows the average frequency of 3 repeated experiments.

Table 2: Univariate ANOVA analysis illustrating the effect of different techniques on growth of multiple shoots after 14 days

\begin{tabular}{|l|l|l|l|l|l|}
\hline Source & Sum of squares & df & Mean square & F & Sig. \\
\hline Between groups & 35182.083 & 3 & 11727.361 & 23.247 & .000 \\
Within groups & 16142.889 & 32 & 504.465 & & \\
Total & 51324.972 & 35 & & & \\
\hline
\end{tabular}

Table 3: Multiple comparison test for growth of multiple shoots of A. paniculata using different culture techniques after 14 days

\begin{tabular}{|c|c|c|c|c|}
\hline Target (I) & Target (J) & Mean difference (I-J) & Std. Error & Sig \\
\hline \multirow[t]{3}{*}{ Solid } & aliq & $-29.22222^{*}$ & 10.58789 & .009 \\
\hline & ${ }^{b} \mathrm{Liq}+\mathrm{bp}$ & $-77.66667^{*}$ & 10.58789 & .000 \\
\hline & ${ }^{\mathrm{d}} \mathrm{Liq}+\cot$ & -2.33333 & 10.58789 & .827 \\
\hline \multirow[t]{3}{*}{ Liquid } & ${ }^{b} l i q+b p$ & $-48.44444^{*}$ & 10.58789 & .000 \\
\hline & cliq+cotton & $26.88889^{*}$ & 10.58789 & .016 \\
\hline & ${ }^{\mathrm{d}}$ solid & $29.22222^{*}$ & 10.58789 & .009 \\
\hline \multicolumn{5}{|l|}{ Liquid } \\
\hline \multirow[t]{3}{*}{ Blotting paper } & aliq & $48.44444^{*}$ & 10.58789 & .000 \\
\hline & ${ }^{\mathrm{c}} \mathrm{Liq}+\mathrm{cotton}$ & $75.33333^{*}$ & 10.58789 & .000 \\
\hline & ${ }^{\mathrm{d}}$ solid & $77.66667^{*}$ & 10.58789 & .000 \\
\hline \multirow[t]{3}{*}{ Liquid Cotton } & aliq & $-26.88889^{*}$ & 10.58789 & .016 \\
\hline & bliq+bp & $-75.33333^{*}$ & 10.58789 & .000 \\
\hline & ${ }^{\mathrm{d}}$ solid & 2.33333 & 10.58789 & .827 \\
\hline
\end{tabular}

Observations were recorded after 14 days of inoculation. ${ }^{\text {aLiq: }}$ Liquid

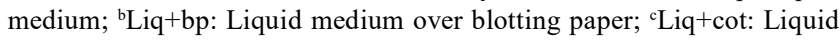
mediumover cotton; ${ }^{\mathrm{d}}$ solid: semi solid medium with $8 \%$ agar. Based on observed means the mean difference is significant at the 0.05 level.
The analysis was carried out through two-way analysis of variance (ANOVA) for on all data under the different techniques for rapid production of multiple shoots. The individual test for the experiment's significance was tested in Post-Hoc analysis through multiple comparison tests of different techniques (Table 3 and 6). The data was evaluated through two-way ANOVA for the overall data of different techniques for shoot proliferation. The experiment with different techniques was found significant at LSD (Least significant difference) $\leq 0.05$ in terms of number of multiple shoots (Table 4 and 7).

Table 4: One-way analysis of multiple shoots growth using different techniques in A. paniculata after 21 days

\begin{tabular}{|l|c|c|}
\hline Culture techniques & Mean & Std error \\
\hline Semi solid & 36.8889 & 4.16815 \\
Liquid & 71.6667 & 8.11891 \\
Liquid media over blotting paper & 131.6667 & 11.98958 \\
Liquid media over cotton & 39.0000 & 2.59272 \\
Total & 69.8056 & 7.43200 \\
\hline
\end{tabular}

Observations were recorded after 21 days of inoculation. The experiment was repeated thrice by maintaining minimum of 9 replicates each time. Each replicate consists of $15 \pm 3$ healthy shoots. Mean is the average response of 9 replicates and the mean \% value in the table shows the average frequency of 3 repeated experiments.

Table 5: Univariate ANOVA analysis illustrating the effect of different techniques on growth of multiple shoots after 21 days

\begin{tabular}{|l|l|l|l|l|l|}
\hline Source & Sum of squares & df & Mean square & F & Sig. \\
\hline Between groups & 52764.750 & 3 & 17588.250 & 33.440 & .000 \\
Within groups & 16830.889 & 32 & 525.965 & & \\
Total & 69595.639 & 35 & & & \\
\hline
\end{tabular}

Table 7: Multiple comparison tests for growth of multiple shoots of A. paniculata in different techniques after 21 days

\begin{tabular}{|c|c|c|c|c|}
\hline Target (I) & Target (J) & Mean difference (I-J) & Std. Error & Sig \\
\hline \multirow[t]{3}{*}{ Solid } & aliq & $-34.77778^{*}$ & 10.81116 & .003 \\
\hline & ${ }^{b}$ Liq_bp & $-94.77778^{*}$ & 10.81116 & .000 \\
\hline & ${ }^{\mathrm{d}}$ Liq_cotton & -2.11111 & 10.81116 & .846 \\
\hline \multirow[t]{3}{*}{ Liquid } & bliq_bp & $-60.00000^{*}$ & 10.81116 & .000 \\
\hline & cliq_cotton & $32.66667^{*}$ & 10.81116 & .005 \\
\hline & d solid & $34.77778^{*}$ & 10.81116 & .003 \\
\hline \multicolumn{5}{|l|}{ Liquid } \\
\hline \multirow[t]{3}{*}{ Blotting paper } & aliq & $60.00000^{*}$ & 10.81116 & .000 \\
\hline & 'Liq_cotton & $92.66667^{*}$ & 10.81116 & .000 \\
\hline & ${ }^{\mathrm{d}}$ solid & $94.77778^{*}$ & 10.81116 & .000 \\
\hline \multirow[t]{3}{*}{ Liquid Cotton } & aliq & $-32.66667^{*}$ & 10.81116 & .005 \\
\hline & bliq_bp & $-92.66667^{*}$ & 10.81116 & .000 \\
\hline & ${ }^{\mathrm{d}}$ solid & 2.11111 & 10.81116 & .846 \\
\hline
\end{tabular}

Observations were recorded after 21 days of inoculation. ${ }^{a}$ Liq: Liquid medium; ' ${ }^{\mathrm{Liq}}+\mathrm{bp}$ : Liquid medium over blotting paper; ${ }^{\mathrm{C}} \mathrm{Liq}+\mathrm{cot}$ : Liquid medium over cotton; ${ }^{\mathrm{d}}$ solid: semi solid medium with $8 \%$ agar. Based on observed means the mean difference is significant at the 0.05 level.

The growth of shoots in liquid medium was encountered with thickening of leaves showing fructification tendency which were not suitable further differentiation and also could not be sub-cultured for multiplication. Apart from that, shoots growing in solid, only 
liquid, over cotton on liquid medium became brown and showed affinity towards senescence within two weeks. The shoots became dark green and no further shoot formation with emergence of new shoot buds was observed. However, amongst the culture techniques evaluated shoots grown in liquid media over blotting paper was found best with higher multiplication rate of healthy green shoots (Figure 5). Although, in liquid media over blotting paper culture technique a negligible sign of leaf browning was observed at localized areas of shoot bunch, the nodal parts remained healthy and rejuvenated.

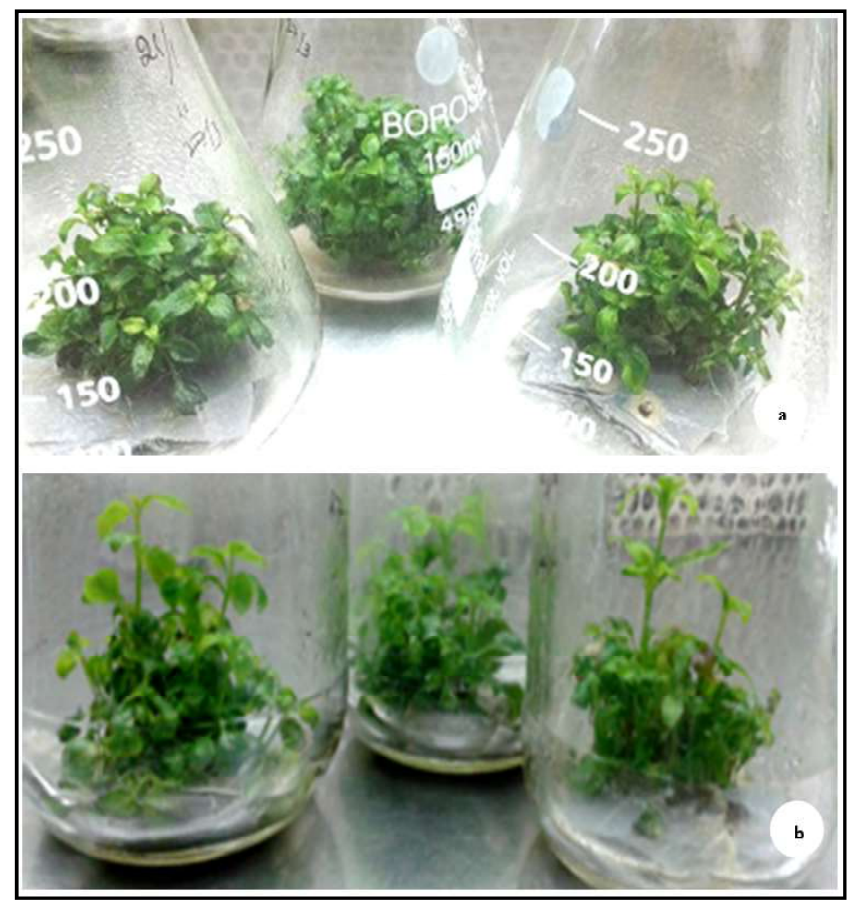

Figure 5: Mass scale multiplication of shoots of $A$. paniculata in liquid media over blotting paper (a) In $250 \mathrm{ml}$ Erlenmeyer flask (b) $300 \mathrm{ml}$ screw capped jam bottles.

\subsection{Andrographolide analysis of rootless multiple shoots} grown using different culture techniques

The amount of andrographolide in shoots by HPLC analysis revealed variation in content a of rootless multiple shoots amongst different culture techniques evaluated. Significantly, the shoots grown in liquid have shown highest andrographolide content, i.e., $4.00 \%$ DW compared to all other culture techniques (Figure 7 and 8). Whereas, in shoots grown in liquid media over blotting paper was $2.35 \%$ DW, liquid media over cotton block was $2.44 \%$ DW without much difference in the content increase. Although, the blotting paper method did not promote higher andrographolide production, but best growth of highly proliferating shoots with increased biomass could be achieved compared to other techniques where early senescence and browning of shoots was a common limitation (Figure 6). The shoots grown in solid media has shown least content of andrographolide with $1.59 \%$ DW. A 2.51 -fold higher andrographolide accumulation was observed in multiple shoots grown in liquid medium than solid.

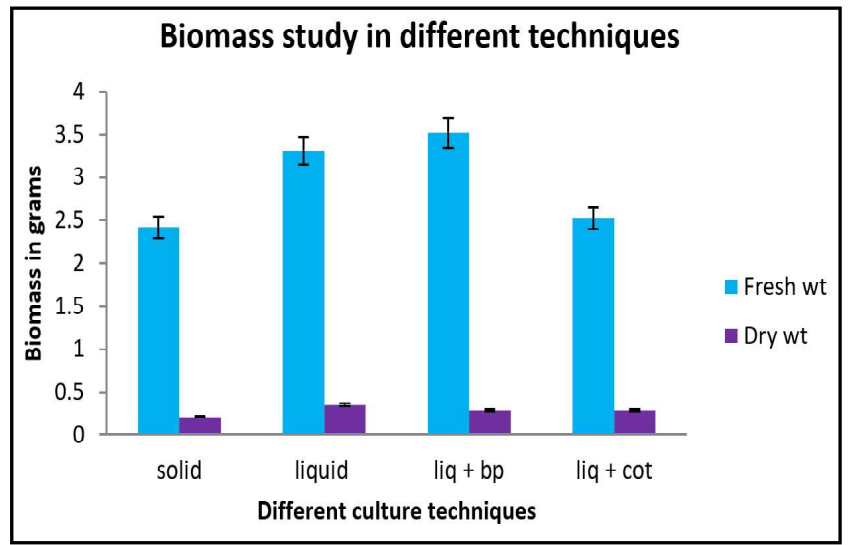

Figure 6: Effect of different culture techniques on biomass production of $A$. paniculata multiple shoots. liq: liquid medium; liq+bp: liquid medium over blotting paper; liq+cot: liquid medium over cotton.

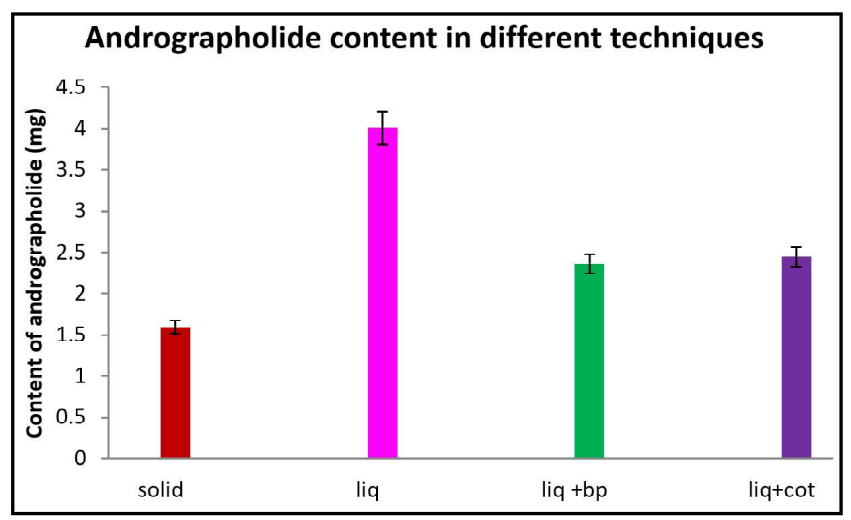

Figure 8: Influence of different culture techniques on andrographolide content in A. paniculata. multiple shoots. liq: liquid medium; liq+bp: liquid medium over blotting paper; liq+cot: liquid medium over cotton.

\section{Discussion}

The germination of immature green seeds was faster in a few days compared to mature pod seeds. Similar results were obtained previously with immature pod seeds (Purkayastha et al., 2008). In an earlier study of sub-culturing similar results were observed with A. paniculata and Withania somnifera seedlings on MS medium supplemented with BAP $\left(2 \mathrm{mg} \mathrm{l}^{-1}\right)$ for shoot induction (Purkayastha et al., 2008). In another report, BAP was supplemented with spermadine to improve the shoot multiplication in Withania somnifera (Sivanandhan et al., 2013).

The liquid medium compared to solid medium was found advantageous for in vitro propagation of shoots as the media supplementation is easy. besides other advantages. It showed a faster and simple way to increase the biomass of shoots in liquid media compared to solid media from our previous reports (Roy et al., 2009, Zaheer and Giri, 2015). In a previous report after 21 days of culture in temporary immersion systems, the biomass of shoots was also found to be 7 times higher and was best in terms of FW and DW in Stevia rebaudiana indicating large scale multiplication potential (Vives et al., 2017). 
In cultivars of Eucalyptus, Bulbine latifolia, B. frutescens and Dianthus caryophyllus the temporary immersion technique was considered better large scale propagation alternative for shoot production and elongation (Ahmadian et al., 2017; Zhang et al., 2018). In Dianthus caryophyllus and Anthurium andreanum shoot length, number of nodes and fresh weight was found to be increased 3 times in temporary immersion system with liquid medium compared to conventional solid medium (Park and Jeong et al., 2019; Martínez-Estrada et al., 2019). These reports of temporary immersion technique supports our finding on the superiority of shoot growth using liquid media over blotting paper for rapid propagation in $A$. paniculata. In the present study, More biomass can be generated in the form of multiple shoots using blotting paper technique compare to other methods. Because, there are several limitations such as, thickening of leaves, callusing at the base of the shoots, browning of leaves, during in vitro propagation of A. paniculata plants using semi solid, liquid in our study and adopting temporary immersion cultures in the past. Generally, in the solid cultures although aeration is possible but uniform nutrient uptake and availability is not appropriate but further the accumulation of $\mathrm{CO}_{2}$ and ethylene, still remain a common problem.
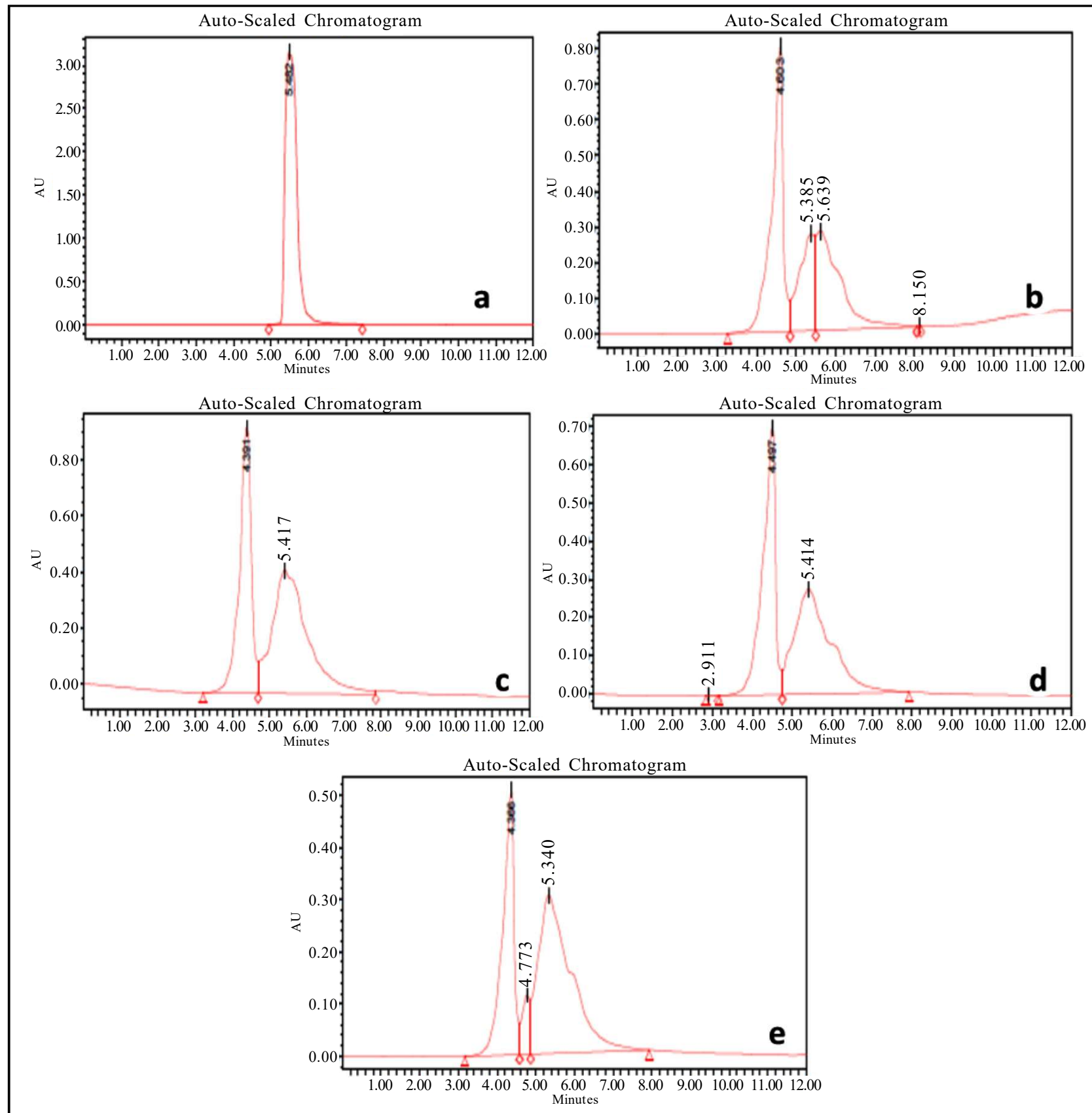

Figure 7: HPLC profile analysis for andrographolide in multiple shoot cultures of A. paniculata. (a) Standard (b) Shoots grown in semi solid media (c) Liquid media (d) Liquid medium over blotting paper (e) Liquid media over cotton. 
On the contrary in general, comparatively nutrient uptake is uniform in liquid media grown cultures. However, the thickening of leaves with the symptom of hyperhydricity is a common limitation in liquid cultures which leads to oxidative stress, malformation of leaves and other physiological disorders even in temporary immersion methods (Berthouly and Etienne 2005; Chakrabarty et al., 2006; Regueira et al., 2017). To circumvent these problems, the temporary immersion technique could serve as a better alternative. Similar study on these three culture techniques, i.e., solid, liquid, temporary immersion showed the increase in shoot multiplication and biomass in temporary immersion techniques. It has several advantages over other culture techniques such as prevention of asphyxia and hyperhydricity (Etienne and Berthouly, 2002). However, practically the temporary immersion technique is tedious and involves constant monitoring for the time of temporary immersion. On the other hand our present finding provides an extremely simple technique through the use of easily available lowcost blotting paper culture method to generate multiple shoots at increased rate in laboratory conditions for enhanced biomass production. In a previous report, steviol glycosides production was best in Stivea rebaudiana using temporary immersion technique (Vives et al., 2017). In another report the temporary immersion technique had also revealed positive effect in Digitalis plants for cardiotonic digoxin and lanatoside $\mathrm{C}$ accumulation (Arano-Avalos et al., 2019; Pérez-Alonso et al., 2009).

\section{Conclusion}

An improved technique has been developed to establish and quicken the regeneration capacity of $A$. paniculata multiple shoots. This is the first report of $A$. paniculata multiple shoot cultures in liquid media with higher multiplication rate compared to the shoot multiplication in solid medium. It showed a faster and simple way to increase the biomass of shoots in liquid media compared to previous reports. The slow and continuous supplementation of liquid media over blotting paper as support system without the submergence of shoots might be one of the reasons for fast and consistent growth. The blotting paper platform may be facilitating sufficient aeration to the inoculated shoots for obtaining optimum growth. Thus, the improved culture technique in the present study has made a difference in terms of shoot multiplication frequency compared to shoots inoculated onto both liquid and solid medium in the long run. The rapid biomass production using improved technique, subsequent increased production of andrographolide in shorter duration of time may be exploited in vitro as a constant source of this pharmaceutically important bioactive diterpene lactone to meet the demand and for germplasm conservation in curtailing exploitation of $A$. paniculata from its natural habitat.

\section{Acknowledgements}

The authors acknowledge the financial support from Department of Science and Technology (DST)-Promotion of University Research and Scientific Excellence (PURSE) Program-II and University Grant Commission (UGC)-Centre for Potential Excellence in Particular Area (CPEPA), New Delhi, India and fellowship support from UGC-Basic Scientific Research (BSR)-Research Fellowship for Meritorious Students (RFMS), New Delhi, India to MS, AS and BBVB. We also thank Prof. V. Haragopal, Department of Statistics, OU for his support in statistical data analysis.

\section{Conflict of interest}

The authors declare that there are no conflicts of interest in the course of conducting the research. All the authors had final decision regarding the manuscript and decision to submit the findings for publication.

\section{References}

Ahmadian, M.; Babaei, A.; Shokri, S. and Hessami, S. (2017). Micropropagation of carnation (Dianthus caryophyllus L.) in liquid medium by temporary immersion bioreactor in comparison with solid culture. Genet. Eng. Biotechnol. J., 15:309-315.

Al-Qurainy, F.; Nadeem, M.; Khan, S.; Alansi, S.; Tarroum, M. Al-Ameri A. A.; Gaafar, A-R. Z. and Alshameri, A. (2018). Rapid plant regeneration, validation of genetic integrity by ISSR markers and conservation of Reseda pentagyna an endemic plant growing in Saudi Arabia. Saudi J. Biol. Sci., 25:111-116.

Arano-Avalos, S.; Gómez-Merino, FC.; Mancilla-Álvarez, E.; Sánchez-Páez, R. and Bello-Bello, J.J. (2019). An efficient protocol for commercial micropropagation of malanga (Colocasiaesculenta $\mathrm{L}$. Schott) using temporary immersion. Sci. Hortic., pp: 108998.

Avila-Treviño, J.A.; Muñoz-Alemán, J.M.; Pérez-Molphe-Balch, E.; RodríguezSahagún, A. and Morales-Domínguez, J.F. (2017). In vitro propagation from bud and apex explants of Moringaoleifera and evaluation of the genetic stability with RAMP marker. S. Afr. J. Bot., 108:149-156.

Aziz, N. A.; Tan, B.C.; Othman, R.Y. and Khalid, N. (2018). Efficient micropropagation protocol and genome size estimation of an important cover crop, Mucunabracteata DC. exKurz. Plant Cell Tiss. Organ Cult., 132:267-278.

Basu, A.; Guti, S.; Kundu, S.; Das, A.; Das, S. and Mukherjee, A. (2020). Oral andrographolide nanocrystals protect liver from paracetamol induced injury in mice. J. Drug DelivSciTechnol., 55:101406.

Berthouly, M. and Etienne, H. (2005). Temporary immersion systems: A new concept for use liquid medium in mass propagation in: A. K. Hvoslef-Eide and W. Preil, Eds., Liquid Culture Systems or in vitro Plant Propagation, Springer, Dordrecht, pp:165-195.

Bindu, B.B.V.; Srinath, M.; Shailaja, A. and Giri, C.C. (2020). Proteome analysis and differential expression by JA drivenelicitation in Andrographis paniculata (Burm. f.) Wall. exNees using Q-TOFLC-MS/MS. Plant Cell Tiss. Organ Cult., 140:489-504.

Bindu, B.B.V.; Srinath, M.; Shailaja, A. and Giri, C.C. (2017). Comparative protein profile studies and in silico structural/functional analysis of HMGR (ApHMGR) in Andrographis paniculata (Burm. f.) Wall.exNees. Ann. Phytomed., 6:30-44.

Chakrabarty, D.; Park, S.Y.; Ali M.B,; Shin K.S. and Paek, K.Y. (2006). Hyperhydricity in apple: Ultrastuctural and physiological aspects. Tree Physiol., 26:377-388.

Chao, W.W. and Lin, B.F. (2010). Isolation and identification of bioactive compounds in Andrographis paniculata (Chuanxinlian). Chin. Med., 5:17.

Dai, Y.; Chen, S.R.; Chai, L.; Zhao, J.; Wang, Y. and Wang, Y. (2019). Overview of pharmacological activities of Andrographis paniculata and its major compound andrographolide. Crit. Rev. Food Sci. Nutr., 59:S17-S29.

Etienne, H. and Berthouly, M. (2002). Temporary immersion systems in plant micropropagation. Plant Cell Tiss. Organ Cult., 69:215-231.

Gan, L.; Zheng, Y.; Deng, L.; Sun, P.; Ye, J.; Wei, X. and Liu, J. (2019). Diterpenoid lactones with anti-inflammatory effects from the aerial parts of andrographis paniculata. Molecules, 24(15):2726. 
Ghosh, S.; Dasgupta, S. C.; Dasgupta, A. K.; Gomes, A. and Gomes, A. (2020). Gold nanoparticles (AuNPs) conjugated with andrographolide ameliorated viper (Daboia russellii russellii) venom-induced toxicities in animal model. J. Nanosci., 20:3404-3414

Giri, C.C. and Zaheer, M. (2016). Chemical elicitors versus secondary metabolite production in vitro using plant cell, tissue and organ cultures: Recent trends and a sky eye view appraisal. Plant Cell Tiss. Organ Cult., 126:1-18.

Hancke, J.; Burgos R; Caceres, D. and Wikman, G. (1995). A double blind study with a new monodrug Kan Jang: Decrease of symptoms and improvement in the recovery from common colds. Phytother. Res., 9:559-562.

Hoagland, D.R. and Arnon, D.I.; (1938). The water culture method for growing plants without soil. Calif. Agric. Exp. Stn. Circulation, 347:32.

Kumar, R.A.; Sridevi, K.; Kumar, N.V.; Nanduri, S. and Rajagopal, S. (2004). Anticancer and immunostimulatory compounds from Andrographis paniculata. J. Ethnopharmacol., 92:291-295.

Mao, A.A.; Vijayan, D.; Singha, R.N. and Pradhan, S. (2018). In vitro propagation of Rhododendron watti Cowan: A critically endangered and endemic plat from India. In vitro Cell Dev. Biol. Plant, pp:1-9.

Martínez-Estrada, E.; Islas-Luna, B.; Pérez-Sato, J.A. and Bello-Bello, J.J. (2019). Temporary immersion improves in vitro multiplication and acclimatization of Anthurium andreanum Lind. Sci. Hortic., 249:185-191.

Murashige, T. and Skoog, F. (1962). A revised medium for rapid growth and bioassays with tobacco tissue cultures. Physiol. Plant, 15:473-497.

Neeraja, C.; Krishna, P.H.; Reddy, C.S.; Giri, C.C.; Rao, K.V. and Reddy, V.D. (2015). Distribution of Andrographis species in different districts of Andhra Pradesh. Proc. Natl. Acad. Sci. India Sect. B. Biol. Sci., 85:601-606.

Negi, A.S.; Kumar, J.K.; Luqman, S.; Shanker, K.; Gupta, M.M. and Khanuja, S.P.S (2008). Recent advances in plant hepatoprotectives: A chemical and biological profile of some important leads. Med. Res. Rev., 28:746-772.

Padmanabhan, P.; Shukla, M.R.; Sullivan, J.A. and Saxena, P. K. (2017). Iron supplementation promotes in vitro shoot induction and multiplication of Baptisiaaustralis. Plant Cell Tiss. and Organ Cult., 129:145-152.

Pandey, A.K.; Smiley Gulati; Amit Gupta and Tripathi, Y.C. (2019). Variation in andrographolide content among different accessions of Andrographis paniculata. The Pharma Innovation Journal, 8:140-144.

Park, Y.G. and Jeong, B.R. (2019). Growth and development of carnation 'Dreambyul'plantlets in a temporary immersion system and comparisons with conventional solid culture methods. In Vitro Cell DevBiol -Plant 1-10.

Parlapally, S.; Cherukupalli, N.; Bhumireddy, S.R.; Sripadi, P.; Anisetti, R.; Giri, C.C.; Khareedu, V.R. and Reddy Vudem, D.; (2016). Chemical profiling and anti-psoriatic activity of methanolic extract of Andrographis nallamalayana JL Ellis. Nat. Prod. Res., 30:1256-126.

Pérez-Alonso, N.; Capote, A.; Gerth, A. and Jiménez, E. (2012). Increased cardenolides production by elicitation of Digitalis lanata shoots cultured in temporary immersion systems. Plant Cell Tiss. Organ Cult., 110:153-162

Pérez-Alonso, N.; Wilken, D.; Gerth, A. and Jähn, A. (2009). Cardiotonic glycosides from biomass of Digitalis purpurea L. cultured in temporary immersion systems. Plant Cell Tiss. Organ Cult., 99:151-156.
Poolsup, N.; Suthisisang, C.; Prathanturarug, S.; Asawamekin, A. and Chanchareon, U. (2004). Andrographis paniculata in the symptomatic treatment of uncomplicated upper respiratory tract infection: Systematic review of randomized controlled trials. J. Clin. Pharm. Ther., 29:37-45.

Purkayastha, J.; Sugla, T.; Paul, A.; Solleti, S. and Sahoo, L. (2008). Rapid in vitro multiplication and plant regeneration from nodal explants of Andrographis paniculata: A valuable medicinal plant. In vitro Cell Dev. Biol. Plant, 44:442-447.

Regueira, M.; Rial, E.; Blanco, B.; Bogo, B.; Aldrey, A.; Correa, B. and Vidal, N. (2017). Micropropagation of axillary shoots of Salix viminalis using a temporary immersion system. Trees, 1-11.

Roy, S.; Giri, A.; Bhubaneswari, P.; Narasu, M.L. and Giri, C.C. (2009). High frequency plant regeneration, via, direct organogenesis in Andrographis paniculata: An important medicinal plant. Med. Aromat. Plant Sci. Biotechnol., 3:94-96.

Sajeeb, B. K.; Kumar, U.; Halder, S. and Bachar, S.C. (2015). Identification and quantification of Andrographolide from Andrographis paniculata (Burm. f.) Wall.exNees by RP-HPLC method and standardization of its market preparations. Dhaka Univ. J. Pharm. Sci., 14:71-78.

Sarkar, S.; Gopal, P.K.; Chakraborty, B.; Paul, M.; Chowdhury, C. and Paul, S. (2019). 14-Deoxy-11, 12-Didehydroandrographolide: A novel compound isolated from Andrographis paniculata Nees. Induces robust apoptosis in leukemic cells. Pharmacogn. Mag., 15:135.

Schumann, A.; Torras-Claveria, L.; Berkov, S.; Claus, D.; Gerth, A.; Bastida, J. and Codina, C. (2013). Elicitation of galanthamine production by Leucojumaestivumshoots grown in temporary immersion system. Biotechnol. Prog., 29:311-318.

Shailaja, A.; Bhavani, B.; Bindu, V.; Srinath, M. and Giri, C.C. (2018). In silico structural and functional analysis of copalyldiphosphate synthase enzyme in Andrographis paniculata (Burm. f.) Wall.exNees: A plant of immense pharmaceutical value. Ann. Phytomed., 7:69-77.

Sharma, S.N.; Jha, Z. and Sinha, R.K. (2013). Establishment of in vitro adventitious root cultures and analysis of andrographolide in Andrographis paniculata. Nat. Prod. Commun., 8:1045-1047.

Sivanandhan, G.; Arun, M.; Mayavan, S.; Rajesh, M.; Jeyaraj, M. and Dev, G.K. (2012). Optimization of elicitation conditions with methyl jasmonate and salicylic acid to improve the productivity of withanolides in the adventitious root culture of Withaniasomnifera (L.) Dunal. Appl. Biochem. Biotechnol., 168:681-696.

Sivanandhan, G.; Rajesh, M.; Arun, M.; Jeyaraj, M. and Dev, G.K. (2013). Effect of culture conditions, cytokinins, methyl jasmonate and salicylic acid on the biomass accumulation and production of withanolides in multiple shoot culture of Withaniasomnifera (L.) Dunal using liquid culture. Acta Physiol. Plant, 35:715-728.

Srinath, M.; Bindu, B.B.V.; Shailaja, A. and Giri, C.C. (2020). Isolation, characterization and in silico analysis of 3-Hydroxy-3-methylglutarylcoenzyme. A reductase (HMGR) gene from Andrographis paniculata (Burm. f) Nees. Mol. Biol. Rep., 47: 639-654.

Srinath, M.; Shailaja, A.; Bindu. B.B.V. and Giri, C.C. (2017). Characterization of 1-deoxy-D-xylulose 5-phosphate synthase (DXS) protein in Andrographis paniculata (Burm.f.) Wall.ex. Nees: A in silico appraisal. Ann. Phytomed., 6:63-67 
Srivastava, N. and Akhila, A. (2010). Biosynthesis of andrographolide in Andrographis paniculata. Phytochem., 71:1298-1304.

Subramanian, R.; Asmawi, M.Z. and Sadikun, A. (2012). A bitter plant with a sweet future? A comprehensive review of an oriental medicinal plant: Andrographis paniculata. Phytochem Rev., 11:39-75.

Vives, K.; Andújar, I.; Lorenzo, J.C.; Concepción, O.; Hernández, M. and Escalona, M. (2017). Comparison of different in vitro micropropagation methods of Stevia rebaudiana B. including temporary immersion bioreactor (BIT®). Plant Cell Tiss. Organ Cult., 131:195-199.

Widyawaruyanti, A.; Asrory, M.; Ekasari, W.; Setiawan, D.; Radjaram, A.; Tumewu, L. and Hafid, A.F. (2014). In vivo antimalarial activity of Andrographis paniculata tablets. Procedia. Chemistry, 13:101-104.

Xu, Y.; Marshall, R.L. and Mukkur, T.K. (2006). An investigation on the antimicrobial activity of Andrographis paniculata extracts and andrographolide in vitro. Asian J. Plant Sci., 5:527-530.

Yang, S.; Evens, A.M.; Prachand, S.; Singh, A.T.; Bhalla, S.; David, K. and Gordon, L.I. (2010). Mitochondrial-mediated apoptosis in lymphoma cells by the diterpenoid lactone andrographolide, the active component of Andrographis paniculata. Clin. Cancer Res., 16:4755-4768.
Zaheer, M. and Giri, C.C. (2015). Multiple shoot induction and jasmonic versus salicylic acid driven elicitation for enhanced andrographolide production in Andrographis paniculata. Plant Cell Tiss. Organ Cult., 122:553-563.

Zaheer, M. and Giri, C.C. (2017). Enhanced diterpene lactone (andrographolide) production from elicited adventitious root cultures of Andrographis paniculata. Res. Chem. Intermed., 43: 2433-2444.

Zaheer, M. and Giri, C.C. (2017). Influence of cotyledon, hypocotyl extracts and authentic andrographolide on selective Agrobacterium rhizogenes strains growth: A deterrent to hairy root induction in Andrographis paniculata (Burm. f.) Wall. exNees. Ann. Phytomed., 6:51-56.

Zhang, B.; Song, L.; Bekele, L.D.; Shi, J. and Jia, Q. (2018). Optimizing factors affecting development and propagation of Bletillastriata in a temporary immersion bioreactor system. Sci. Hort., 232:121-126.

Zuma, N.; Finnie, J.F. amd Van Staden, J. (2017). In vitro propagation of Bulbinelatifolia (Lf) Schult. and JH Schult.var. latifolia and Bulbinefrutescens (L.) Wild. using a Temporary Immersion System. S. Afr. J. Bot., 109:376-377.

Citation: Aayeti Shailaja, Mote Srinath, Byreddi Bhavani Venkata Bindu and Charu Chandra Giri (2020). Innovative technique for rapid in vitro multiplication of rootless shoots in Andrographis paniculata (Burm. f) Nees: A plant with immense pharmaceutical value. Ann. Phytomed., 9(1):98-106. http://dx.doi.org/10.21276/ap.2020.9.1.11 